\title{
The Incidence and Frequency of Various Causes of Angioedema in Emergency Medicine
}

\author{
Ljerka Karadža-Lapić ${ }^{1}$, Tamara Pikivaca ${ }^{2,3}$, Petra Pervan ${ }^{2,3}$, Josipa Jović Zlatović, \\ Sanja Delin ${ }^{5}$, Ingrid Prkačin ${ }^{2,6}$
}

${ }^{1}$ Department of Otorhinolaryngology, General Hospital Šibenik, Šibenik, Croatia, ${ }^{2}$ University of Zagreb, School of Medicine Zagreb, Zagreb, Croatia, ${ }^{3}$ Public Health Centre Zagreb, Zagreb, Croatia, ${ }^{4}$ Department of Internal Medicine, General Hospital Šibenik, Šibenik, Croatia, ${ }^{5}$ Department of Pediatric, General Hospital Zadar, Zadar, Croatia, ${ }^{6}$ Clinical Hospital Merkur, Department of Internal Medicine/ Emergency Unit, Zagreb, Croatia

\footnotetext{
Correspondence: ljerka.karadzalapic@gmail.com

Tel.: + 38522641360

Fax.: + 38522641262
}

Received: 29 December 2017

Accepted: 4 May 2018

Key words: Angioedema - Emergency Bradykinin - Icatibant - Plasma-derived C1-inhibitor.

\section{Introduction}

Quinckes edema or angioedema (AE) is an transient, localized swelling of the deep dermis or subcutaneous/submucosal tissues (1). Angioedema usually manifests in the upper airway, and the head and neck region $(1,2)$. Histamine and bradykinin are two main mediators involved in AE occurrence,
Objective. Angioedema (AE) is a potentially life-threatening event. We investigated the etiology of AE, with the emphasis on bradykinininduced angioedema treatment in emergency medicine. Methods. The retrospective study included 237 patients with AE, who were examined and treated in two hospitals (group A and B) in Croatia from 2009 to 2016. The location and duration of AE, data about chronic diseases and treatment, potential causative agents (food, drugs, insect bites and chemicals), physical examination data and the subsequent treatment were analyzed. Results. There was no statistical difference regarding age or comorbidities but there was a statistically significant difference in etiology between the groups (Chi-square, $\mathrm{P}=0.03$ ). Renin-angiotensin-aldosterone system (RAAS) blocker induced AE was the main cause of emergency attendance in group A (37.5\%) and among the leading causes in group B (18.8\%). Bradykinin-induced $\mathrm{AE}$ (hereditary angioedema (HAE) and RAAS-AE) were the leading causes in a total of $75(31.5 \%)$ patients. RAAS-AE was treated with glucocorticoids and antihistamines. HAE attacks in both groups $(2 / 7$ patients, $1.5 / 6 \%$ ) were treated with specific therapy. Other causes of $\mathrm{AE}$ in groups A/B were insect bites (15/23 patients, $13.5 / 20 \%)$, use of antibiotics/analgetics (11/17 patients, 9/15\%), gastroesophageal reflux disease ( $10 / 11$ patients, $8 / 9 \%$ ), neoplasms (5/6 patients, $4 / 5 \%$ ) and idiopatic (32/31 patients, $26.5 / 26 \%)$. $21 \%$ of patients were hospitalized. Conclusion. Bradykinin-mediated AE was the main cause of emergency attendance associated with AE. Advances in the treatment of HAE, with case reports of patients with RAAS-AE treated with C1 esterase inhibitor concentrate or bradykinin receptor antagonist, may prove to be a new, reliable and efficacious therapy option. inducing endothelial cell permeability (3-7). Histamine-mediated AE with recognizable triggers, such as an insect bite, food, medication, and rapid onset of swelling, are often accompanied by urticaria and itching (3). Bradykinin-induced angioedema, including hereditary (hereditary angioedema (HAE) types I (due to low level of $\mathrm{C} 1$ ester- 
ase inhibitor (C1 INH)) and II (dysfunctional $\mathrm{C} 1 \mathrm{INH}$ ), or HAE with normal $\mathrm{C} 1$ INH) or nonhereditary forms (nonallergic angiotensin-converting enzyme inhibitors (ACEI) or angiotensin II receptor blockers (ARBs) induced angioedema and acquired $\mathrm{AE}$ due to $\mathrm{C} 1 \mathrm{INH}$ deficiency) with a history of recurrent swelling and abdominal pain, are not associated with urticaria $(3,8$, 9). Differentiation is essential for treatment planning since bradykinin mediated angioedema does not respond to conventional antihistamine and corticosteroid therapies (8). Angioedema due to exposure to external agents (insect bites, food, environmental allergens) is very common. Including gastrooesophageal reflux disease (GERD), it is usually identified by the patients themselves (10). The role of GERD in the development of angioedema is still controversial, especially in children $(10,11)$. Some tumors may produce biogenic amines, such as histamine, and release them into the circulation causing angioedema (12). Acquired $\mathrm{AE}$ with low C1-INH is connected with autoimmunity or malignant lymphoproliferative disorders (13).

Drugs may induce AE by three mechanisms: an allergic IgE-mediated reaction accompanied by urticaria (such as betalactam antibiotics); non-allergic, such as $\mathrm{AE}$ induced by aspirin and nonsteroidal antiinflammatory drugs (NSAID); and the most frequent (10-25\% of all cases, never associated with urticaria) including inhibition of bradykinin degradation, induced by reninangiotensin-aldosterone system (RAAS) blockers, such as ACEI or ARBs $(10,14,15)$. The RAAS plays an important role in the regulation of kidney blood flow and blood pressure, with the emphasis on angiotensinogen, which is changed from angiotensin I to angiotensin II by the angiotensin I-converting enzyme (ACE) (known as kininase II). Angiotensin II is a key factor for the inactivation of bradykinin which originates from the degradation of kininogen by kallikreins. The metabolism of bradykinin does not depend only on ACE. Several other enzymes are involved and a deficiency of any of these enzymes (due to a genetic polymorphism) will increase the risk of developing AE (15-18). This has been observed in black and Hispanic races $(6,15,19,20)$. AE with ACEI therapy (ACEI-AE) is more frequent than for other RAAS blockers, and is between $0.1 \%$ and $2.2 \%$ (6). The development of edema in the upper respiratory tract is unpredictable. The management of ACEI-AE begins by ceasing administration of ACEI as the suspected drug $(6,21)$. It is important to tell the patient not to take any RAAS drugs ever again, such as ARBs, while $4 \%$ of patients who have had ACEI-AE will develop AE when they switch to ARBs (22). The literature suggests that some other drugs that inhibit the mammalian target of rapamycin (mTOR inhibitors), if taken with ACEI, affect the incidence of ACEI-AE (23).There is no approved treatment for this potentially life-threatening situation $(22,24)$. As Craig et al. reported, specific drugs, such as a C1INH concentrate and bradykinin B2 receptor blocker icatibant, which have been approved for acute attacks of HAE type 1 or 2 , successfully resolved attacks of different types of bradykinin-induced $\operatorname{AE}(8,25,26)$.

The goal of this study was to determine the incidence of $\mathrm{AE}$, and whether there is a difference in the causes and frequency of $\mathrm{AE}$ as a major reason for emergency attendance, with special emphasis on bradykinin-induced angioedema frequency and treatment.

\section{Materials and methods}

A retrospective, two-center analysis was conducted of all patients with AE found in the Emergency Units' medical databases. The study included a total of 237 patients with $\mathrm{AE}$ who were examined in the Emer- 
gency Units of two hospitals in Croatia: Merkur Clinical Hospital, Zagreb (120 patients in group A) and the Department of Otorhinolaryngology, Šibenik General Hospital, Šibenik (117 patients in group B) from January 2009 to January 2016. Anamnestic findings (location and duration of AE), data about chronic diseases, treatment (primarily exposure to ACEI, ARBs) and potentially causative agents (food, drugs, insect bites and chemicals) along with the physical examination data and subsequent treatment, were analyzed for each patient with AE. As Zingale at al. proposed, ACEI-AE was diagnosed when angioedema was repeatedly present during ACEI therapy and ended upon withdrawal of the medication (10).

Since there is still no standardized severity scoring system for $\mathrm{AE}$, we graduated $\mathrm{AE}$ as grade $0=$ no local reaction; grade $1=$ mild (isolated local reaction of the skin or mucosa); grade $2=$ intermediate (involves more distant skin; upper airway); grade $3=$ severe (potentially life-threatening condition manifesting with laryngeal symptoms); grade $4=$ severe multi-system reaction. A composite score was calculated using the visual analog scale, with intensity ranging from 0 to 10 (higher scores indicating more severe symptoms), using the average of the measurements for the six symptoms (pain, shortness of breath, dysphagia, change in voice, sensation of a foreign body, feeling of pressure) as proposed by Bas (7).

\section{Statistical analysis}

Data were described using descriptive statistical methods. Differences in categorical variables were tested with the Chi-square test. The normality of the distribution of numerical variables was tested by ShapiroWilk's test. All P values were two-sided. The level of significance was set at Alpha $=0.05$. The statistical analysis was performed using STATISTICA 13.1.

\section{Results}

The median age in groups $\mathrm{A}$ and $\mathrm{B}$ was 51.7 years, with $50.5 \%$ males (Table 1 ). The graduation of AE in this study was generally mild, characterized by mean severity scores of 1 or $2(20 \%)$ on a scale of 0 to 4 . The mean composite score on a visual-analogue scale of 0 to 10 was approximately 3 .

The etiology of AE is shown in Table 1. Bradykinin-induced $\mathrm{AE}$ (ACEI/ARB and $\mathrm{HAE}$ ) was the leading known cause of $\mathrm{AE}$ in the investigated group, in a total of 75 (31.5\%) patients. AE caused by ACEI/ARB blockers was present in 67 (28\%) patients. Patients with ACEI-AE were older and there were more females represented $(70.5 \%$ female; mean age, $63.4 \pm 11.5$ years) when compared to all AE patients. The locations of AE included swelling of the face and lips (48.1\% of patients), tongue $(37.5 \%)$, larynx $(12.5 \%)$ and upper airways (2.9\%). The duration of exposure to ACEI was between 1 and 721 days with a median of 452 days. Duration of AE symptoms was from 2 to 5 days. All patients with ACEI-AE had normal C1-inhibitor levels. There was no statistically significant difference regarding age or comorbidities (hypertension, diabetes, heart failure, kidney disease) but there was a statistically significant difference in etiology between the groups (Chi-square, $\mathrm{P}=0.03$ ). All the patients were under the appropriate therapy for comorbidities. In group A the patients used drugs in their chronic therapy more than in group $B$ (such as diuretics in fixed combination with ACEI, such as ramipril in 80\%). All investigated patients with symptoms of $\mathrm{AE}$, except HAE patients $(3.8 \%)$, were treated with antihistamines, corticosteroids and epinephrine if needed (Table 1.).

Twenty-one patients (8.9\%) diagnosed with GERB were also treated with proton pump inhibitors (PPI) intravenously. Fresh frozen plasma was administered success- 
Table 1. Demographic and clinical characteristics of patients with angioedema

\begin{tabular}{|c|c|c|c|c|c|}
\hline Characteristics & Group A & Group B & Treatment & Total & $\mathrm{P}^{*}$ \\
\hline \multicolumn{6}{|l|}{ Gender (N; \%) } \\
\hline Male & $62(51.7)$ & $60(51.3)$ & - & $122(51.5)$ & \multirow{2}{*}{0.95} \\
\hline Female & $58(48.3)$ & $57(48.7)$ & - & & \\
\hline Age (Year, Median, IQR) & $52.1(41.8-63)$ & $50.8(40.2-65)$ & - & $51.7(40-60)$ & 0.34 \\
\hline \multicolumn{6}{|l|}{ Etiology $(\mathrm{N} ; \%)$} \\
\hline ACEI/ARB & 45 (37.5) & $22(18.8)$ & $\mathrm{A}+\mathrm{C}$ & $67(28.3)$ & \multirow{7}{*}{0.03} \\
\hline Idiopathic & $32(26.5)$ & $31(26.5)$ & $98.4 \% \mathrm{~A}+\mathrm{C} 1.6 \% \mathrm{FFP}$ & $63(26.6)$ & \\
\hline Insect byte & $15(13.5)$ & $23(19.7)$ & $\mathrm{A}+\mathrm{C}$ & $38(16)$ & \\
\hline Antibiotics; NSAID; OTC & $11(9)$ & $17(14.5)$ & $A+C$ & $28(11.8)$ & \\
\hline GERD & $10(8)$ & $11(9.4)$ & $\mathrm{A}+\mathrm{C}+\mathrm{PPI}$ & $21(8.9)$ & \\
\hline Neoplasms & $5(4)$ & $6(5.1)$ & $\mathrm{A}+\mathrm{C}$ & $11(4.6)$ & \\
\hline HAE & $2(1.5)$ & $7(6)$ & specific & $9(3.8)$ & \\
\hline Total (n) & $120(100)$ & $117(100)$ & & $237(100)$ & \\
\hline
\end{tabular}

${ }^{*}$ Chi-square test; IQR=interquartile range; $\mathrm{ACEl}=$ angiotensin-converting enzyme inhibitors; $\mathrm{ARB}=$ angiotensin $\|$ receptor blockers; NSAID=NonSteroidal anti-inflammatory drugs; $G E R D=$ Gastroesophageal reflux disease; $\mathrm{HAE}=$ Hereditary angioedema; $\mathrm{N}=\mathrm{Number}$ of patients; $\mathrm{A}+\mathrm{C}=$ Antihistamines+corticosteroids; $\mathrm{FFP}=$ Fresh frozen plasma; $\mathrm{PPI}=$ Proton pump inhibitor; OTC=Over the counter.

fully in only one patient in group A, when standard therapy failed. HAE patients were hospitalized for specific therapy, such as C1-INH concentrate (plasma derived or recombinant) or icatibant. In all patients presenting with mild $\mathrm{AE}$ (the majority of the population), monitoring in hospital for at least $6 \mathrm{~h}$ was advised. Patients with clinically significant obstruction of the upper airway (21\%) were hospitalized in the intensive care unit or the Department of Otorhinolaryngology for a few days. There was no need for tracheostomy in any patient with ACEI-AE in either group. Tracheostomy was a lifesaving treatment for one patient in group $B$ with HAE.

\section{Discussion}

Recent studies have revealed $\mathrm{AE}$ as the most frequent and increasing disorder that results in hospitalization (14). In comparison with the study by Loftus et al., twice as many patients $(21 \%)$ needed to be hospitalized for severe angioedema in our investigation (15). In $26.5 \%$ patients in group $\mathrm{B}$ the cause of $\mathrm{AE}$ was unidentified, which makes differential diagnosis and management even more challenging, especially in general hospitals with limited diagnostic and therapeutic tools. The role of GERD or Helicobacter pylori infection in AE remains unclear. Recent studies have presented the opposite results of AE resolution connected with eradication of Helicobacer pylori (10, 27-29). Patients indicating GERD angioedema etiology in this study $(8.9 \%)$ were treated additionally with PPI. This is the first study in Croatia to analyze the frequency and treatment of bradykinin-induced angioedema as a major cause of emergency attendance. This investigation showed an etiological statistically significant difference between the groups (Chisquare, $\mathrm{P}=0.03$ ) but the same therapeutic pattern in both clinical and general hospital centers. $20-45 \%$ of the patients admitted to the emergency rooms for suspicion of $\mathrm{AE}$ are suffering from an $\mathrm{AE}$ mediated by bradykinin $(6,15)$. However, reliable tests that can differentiate bradykinin angioedema from angioedema due to other causes are still not routinely available. In recent years, 
the growth of the use of RAAS blockers has resulted in an increased prevalence of angioedema. The causes of AE listed in Table 1 show that ACEI/ARB was the main cause of emergency attendance in group A (37.5\%) and among the leading causes in group B $(18.8 \%)$. It occurs very often in patients who use several drugs for chronic therapy, such as diuretics (as in group A), accentuating the burden of ACEI among the at-risk population, especially in female patients, with wellknown higher prevalence noticed in $70.5 \%$ females in our investigation. AE is characterized by a local, transient, asymmetrical, sudden and painful swelling of the subcutaneous (facial) and submucosal (oropharyngeal and laryngeal) tissues that occasionally requires tracheostomy as a life-saving treatment, as it did in one patient with HAE in our study (6). If ACEI is the unrecognized cause of angioedema, it relapses with ACEI therapy, as was the case in this study. The drugs commonly used to treat histamine-induced AE of allergic origin (glucocorticoids, antihistamines, epinephrine) are ineffective against bradykinin-induced $\operatorname{AE}(3,6)$. In the investigated groups, ACEI-AE angioedema persisted for 2-4 days with poor resolution using these therapeutics. That emphasizes the need for new therapeutic solutions, especially when the patient's airway is compromised. Specific medications (plasma derived or recombinant $\mathrm{C} 1$-INH concentrate, icatibant) for HAE or acquired AE might be the treatment of choice, as has been demonstrated in numerous studies $(21,30-33)$.

There is a lack of studies using large cohorts of patients with ACEI-AE. The patients with ACEI-AE included in this study were not treated with C1-INH concentrate or icatibant, although in one patient with severe $\mathrm{AE}$ of the tongue, poor resolution of $\mathrm{AE}$ was noticed. However, the recent studies by Straka and Sinert et al. do not support the efficacy of a bradykinin B2 receptor antagonist in ACEI-AE $(34,35)$. Fresh frozen plasma that contains natural $\mathrm{ACE}$ and $\mathrm{C1}$ INH effectively treats ACEI-AE, and was successfully applied in one patient with an unknown cause of AE (6). Plasma derived or recombinant $\mathrm{C} 1-\mathrm{INH}$ concentrate and icatibant were successfully administered during HAE attacks in all the investigated patients (3.8\%) in groups A and B (36).

\section{Conclusion}

$\mathrm{AE}$ resulting from bradykinin-induced $\mathrm{AE}$ (ACEI/ARB and HAE) was the main cause of emergency attendance of patients. Identifying the cause and withdrawal of ACEI is key to management. Mild cases of ACEI-AE may respond to antihistamine or corticosteroid therapy, but moderate to severe cases do not. Advances in the treatment of HAE and case reports of patients with ACEI-AE treated with $\mathrm{C} 1-\mathrm{INH}$ concentrate or bradykinin receptor antagonist show that they may be a safe and efficacious therapeutic option for AE.

What is already known on this topic

Angioedema (AE) is a transient, localized swelling usually manifested in the upper airway, causing potentially life-threatening swelling of the mouth and throat. The most frequent mechanism of AE induced by drugs (10-25\% of all cases, never associated with urticaria) includes inhibition of bradykinin degradation, induced by the renin-angiotensin-aldosterone system, such as angiotensin-converting enzyme inhibitors or angiotensin II receptor blockers. There is no approved treatment for this potentially life-threatening situation.

\section{What this study adds}

This is the first study in Croatia analyzing the frequency and treatment of bradykinin-induced angioedema as a cause of emergency attendance. Bradykinin-induced AE was the leading cause in the investigated group in a total of $75(31.5 \%)$ patients. Our study confirmed the poor response to glucocorticoid, antihistamine and epinephrine treatment in severe $A E$, and the need for new therapeutic options to improve resolution of $A E$.

Authors' contributions: Conception and design: LjKL and IP; Acquisition, analysis and interpretation of data: LjKL, TP and JJZ; Drafting the article: LjKL and IP; Revising it critically for important intellectual content IP, PP and SD; Approved final version of the manuscript: LjKL, TP, PP, JJZ, SD, IP. 
Conflict of interest: The authors declare that they have no conflict of interest.

\section{References}

1. Bernstein JA, Moellman J. Emerging concepts in the diagnosis and treatment of patients with undifferentiated angioedema. Int J Emerg Med. 2012;5(1):39.

2. Lin RY, Levine RJ, Lin H. Adverse drug effects and angioedema hospitalizations in the United States from 2000 to 2009. Allergy Asthma Proc. 2013;34(1):65-71.

3. Cicardi M, Suffritti C, Perego F, Caccia S. Novelties in the Diagnosis and Treatment of Angioedema. J Investig Allergol Clin Immunol. 2016;26(4):21221; quiz two pages after page 21 .

4. Lewis LM. Angioedema: etiology, pathophysiology, current and emerging therapies. J Emerg Med. 2013;45(5):789-96.

5. Kim SJ, Brooks JC, Sheikh J, Kaplan MS, Goldberg BJ. Angioedema deaths in the United States, 1979-2010. Ann Allergy Asthma Immunol. 2014;113(6):630-4.

6. Inomata N. Recent advances in drug-induced angioedema. Allergol Int. 2012;61(4):545-57.

7. Bas M. The Angiotensin-Converting-Enzyme-Induced Angioedema. Immunol Allergy Clin North Am. 2017;37(1):183-200.

8. Craig TJ, Bernstein JA, Farkas H, Bouillet L, Boccon-Gibod I. Diagnosis and treatment of bradykinin-mediated angioedema: outcomes from an angioedema expert consensus meeting. Int Arch Allergy Immunol. 2014;165(2):119-27.

9. Hahn J, Hoffmann TK, Bock B, Nordmann-Kleiner M, Trainotti S, Greve J. Angioedema. Dtsch Arztebl Int. 2017;114(29-30):489-96.

10. Zingale LC, Beltrami L, Zanichelli A, Maggioni L, Pappalardo E, Cicardi B, et al. Angioedema without urticaria: a large clinical survey. CMAJ. 2006;175(9):1065-70.

11. Rosen R, Mitchell PD, Amirault J, Amin M, Watters K, Rahbar R. The Edematous and Erythematous Airway Does Not Denote Pathologic Gastroesophageal Reflux. J Pediatr. 2017;183:127-31.

12. Rodriguez Trabado A, Riesco Miranda JA, Porcel Carreno S, Rodriguez Martin E, Fletes Peral C, Jimenez Timon S, et al. Angioedema as a single manifestation of carcinoid syndrome in a bronchial carcinoid tumor. Allergol Immunopathol (Madr). 2004;32(4):235-7.

13. Otani IM, Banerji A. Acquired C1 Inhibitor Deficiency. Immunol Allergy Clin North Am. 2017;37(3):497-511.
14. Lin RY, Cannon AG, Teitel AD. Pattern of hospitalizations for angioedema in New York between 1990 and 2003. Ann Allergy Asthma Immunol. 2005;95(2):159-66.

15. Loftus PA, Tan M, Patel G, Lin J, Helman S, Badhey A, et al. Risk factors associated with severe and recurrent angioedema: an epidemic linked to ACEinhibitors. Laryngoscope. 2014;124(11):2502-7.

16. Byrd JB, Touzin K, Sile S, Gainer JV, Yu C, Nadeau J, et al. Dipeptidyl peptidase IV in angiotensinconverting enzyme inhibitor associated angioedema. Hypertension. 2008;51(1):141-7.

17. Duan QL, Nikpoor B, Dube MP, Molinaro G, Meijer IA, Dion P, et al. A variant in XPNPEP2 is associated with angioedema induced by angiotensin Iconverting enzyme inhibitors. Am J Hum Genet. 2005;77(4):617-26.

18. Brown T, Gonzalez J, Monteleone C. Angiotensinconverting enzyme inhibitor-induced angioedema: A review of the literature. J Clin Hypertens (Greenwich). 2017;19(12):1377-82.

19. Vleeming W, van Amsterdam JG, Stricker BH, de Wildt DJ. ACE inhibitor-induced angioedema. Incidence, prevention and management. Drug Saf. 1998;18(3):171-88.

20. Brown NJ, Vaughan DE. Angiotensin-converting enzyme inhibitors. Circulation. 1998;97(14):141120 .

21. Bas M, Greve J, Stelter K, Havel M, Strassen U, Rotter $\mathrm{N}$, et al. A randomized trial of icatibant in ACE-inhibitor-induced angioedema. N Engl J Med. 2015;372(5):418-25.

22. Beavers CJ, Dunn SP, Macaulay TE. The role of angiotensin receptor blockers in patients with angiotensin-converting enzyme inhibitor-induced angioedema. Ann Pharmacother. 2011;45(4):5204.

23. Duerr M, Glander P, Diekmann F, Dragun D, Neumayer $\mathrm{HH}$, Budde K. Increased incidence of angioedema with ACE inhibitors in combination with $\mathrm{mTOR}$ inhibitors in kidney transplant recipients. Clin J Am Soc Nephrol. 2010;5(4):703-8.

24. Nosbaum A, Bouillet L, Floccard B, Javaud N, Launay D, Boccon-Gibod I, et al. Management of angiotensin-converting enzyme inhibitor-related angioedema: recommendations from the French National Center for Angioedema [in French]. Rev Med Interne. 2013;34(4):209-13.

25. Moellman JJ, Bernstein JA. Diagnosis and management of hereditary angioedema: an emergency medicine perspective. J Emerg Med. 2012;43(2):391-400.

26. Markovic AS, Rozmanic V, Anic B, Aberle N, Racic G, Novak S, et al. Guidelines for the diagnosis 
and treatment of hereditary angioedema [in Croatian]. Lijec Vjesn. 2014;136(5-6):117-29.

27. Kohli S, Mahajan VK, Rana BS, Mehta KS, Raina RK, Chauhan PS, et al. Clinicoepidemiologic Features of Chronic Urticaria in Patients with versus without Subclinical Helicobacter pylori Infection: A Cross-Sectional Study of 150 Patients. Int Arch Allergy Immunol. 2018;175(1-2):114-20.

28. Rasooly MM, Moye NA, Kirshenbaum AS. Helicobacter pylori: A significant and treatable cause of chronic urticaria and angioedema. Nurse Pract. 2015;40(10):1-6.

29. Mogica-Mogica JD, Gomez-Lopez VM. Association between Helicobacter pylori and allergic and non-allergic chronic urticaria [in Spanish]. Rev Alerg Mex. 2013;60(4):161-3.

30. Lipski SM, Casimir G, Vanlommel M, Jeanmaire M, Dolhen P. Angiotensin-converting enzyme inhibitors-induced angioedema treated by $\mathrm{C} 1$ esterase inhibitor concentrate (Berinert(R)): about one case and review of the therapeutic arsenal. Clin Case Rep. 2015;3(2):126-30.

31. Botnaru T, Robert A, Mottillo S. Icatibant Compared to Steroids and Antihistamines for ACE-Inhibitor-Induced Angioedema. CJEM. 2017;19(2):159-62.
32. Nielsen EW, Gramstad S. Angioedema from angiotensin-converting enzyme (ACE) inhibitor treated with complement 1 (C1) inhibitor concentrate. Acta Anaesthesiol Scand. 2006;50(1):120-2.

33. Gelee B, Michel P, Haas R, Boishardy F. Angiotensin-converting enzyme inhibitor-related angioedema: emergency treatment with complement C1 inhibitor concentrate [in French]. Rev Med Interne. 2008;29(6):516-9.

34. Straka BT, Ramirez CE, Byrd JB, Stone E, Woodard-Grice A, Nian H, et al. Effect of bradykinin receptor antagonism on ACE inhibitor-associated angioedema. J Allergy Clin Immunol. 2017;140(1):242-8.e2.

35. Sinert R, Levy P, Bernstein JA, Body R, Sivilotti MLA, Moellman J, et al. Randomized Trial of Icatibant for Angiotensin-Converting Enzyme Inhibitor-Induced Upper Airway Angioedema. J Allergy Clin Immunol Pract. 2017;5(5):1402-9.e3.

36. Karadza-Lapic L, Korosec P, Silar M, Kosnik M, Cikojevic D, Lozic B, et al. Frequent life-threatening laryngeal attacks in two Croatian families with hereditary angioedema due to $\mathrm{C} 1$ inhibitor deficiency harbouring a novel frameshift mutation in SERPING1. Ann Med. 2016;48(7):485-91. 